\title{
miR-191 Inhibition Induces Apoptosis Through Reactivating Secreted Frizzled- Related Protein-1 in Cholangiocarcinoma
}

\author{
Peng-Cheng Kang ${ }^{\mathrm{a}} \quad$ Kai-Ming Leng ${ }^{\mathrm{a}} \quad$ Yue-Ping Liu ${ }^{\mathrm{a}}$ Yang Liu ${ }^{\mathrm{b}} \quad \mathrm{Yi} \mathrm{Xu}^{\mathrm{a}}$ Wei Qin $^{\mathrm{a}}$ \\ Jian-Jun Gao ${ }^{a}$ Zhi-Dong Wang ${ }^{a}$ Sheng Tai ${ }^{a}$ Xiang-Yu Zhong ${ }^{a}$ Yun-Fu Cui ${ }^{a}$ \\ aDepartment of Hepatopancreatobiliary Surgery, Second Affiliated Hospital of Harbin Medical \\ University, Harbin, 'Department of Clinical Biochemistry Laboratory, the 4th Affiliated Hospital of \\ Harbin Medical University, Harbin, China
}

\section{Key Words}

Cholangiocarcinoma $\cdot \operatorname{miRNA} \cdot \mathrm{miR}-191 \cdot \mathrm{SFRP} 1 \cdot$ Cell survival

\begin{abstract}
Background/Aims: Cholangiocarcinoma (CCA) is one of the most common malignant tumors of the biliary tract originating from biliary epithelial cells. Although many therapeutic strategies have been developed to treat CCA, the survival rate for CCA patients is still quite low. Thus it is urgent to elucidate the pathogenesis of CCA and to explore novel therapeutic targets. miR-191 has been shown to be associated with many human solid cancers, but the function of miR-191 in CCA is still poorly understood. Methods: We first investigated the expression level of miR191 in human CCA tissues and cell lines with quantitative real-time PCR (qRT-PCR). The effects of miR-191 on CCA cells were determined by Cell Counting Kit- 8 assay, colony formation assay and acridine orange/ethidium bromide staining. Finally, we utilized qRT-PCR, western blot and luciferase reporter assays to verify the miR-191 target gene. Results: We showed that miR191 was up-regulated in CCA cell lines and patients. Knockdown of miR-191 by transfection of its inhibitor sequence blocked RBE cells viability and induced apoptosis of RBE cells. Both qRT-PCR and western blot analysis showed that the secreted frizzled-related protein-1 (sFRP1) level was negatively correlated with that of miR-191. Luciferase assay validated that SFRP1 was a direct target of miR-191. Moreover, knockdown of miR-191 led to suppression of Wnt/ $\beta$ catenin signaling activation. Co-transfection of sFRP1 small interfering RNA (siRNA) and miR191 inhibitor re-activated the Wnt/ $\beta$-catenin signaling pathway as detected by an increased level of $\beta$-catenin and phosphorylation of GSK-3 $\beta$, and restored the expression of survivin and c-myc in RBE cells. Co-transfection of sFRP1 siRNA with miR-191 inhibitor restored the colony formation ability and viability of RBE cells. Conclusion: Taken together, our results demonstrate a novel insight into miR-191 biological function in CCA . Our findings suggest that miR-191 is a potential therapeutic target of CCA treatment.

P.-C. Kang, K.-M. Leng and Y.-P. Liu contributed equally to this work.

Yun-Fu Cui

and Xiang-Yu Zhong

Department of Hepatopancreatobiliary Surgery, Second Affiliated Hospital of Harbin

Medical University, Harbin, Heilongjiang 150001 (China)

Tel. 86-451-86605113, E-Mail yfcui777@hotmail.com; zhongxiangyu@hrbmu.edu.cn
\end{abstract}




\section{Cellular Physiology Cell Physiol Biochem 2018;49:1933-1942

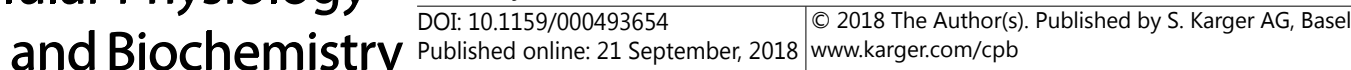 \\ Kang et al.: miR-191 Inhibition Induces Cholangiocarcinoma Cell Apoptosis}

\section{Introduction}

Cholangiocarcinoma (CCA) is one of the most common malignancies originating from biliary epithelialcells [1]. CCA usually metastasize and cause relapse because it is commonly diagnosed in the advanced stage of the disease, and leads to poor prognosis [2-4]. Many studies have revealed that numerous genes are involved in CCA [5-9] and many therapeutic strategies have been developed to treat CCA [10-12]; however, the survival rate for CCA patients is still low [13]. In this case, the pathogenesis and progression of this malignancy remains to be investigated and new therapeutic targets need to be explored.

MicroRNAs (miRNAs) are 20 to 25 nucleotide-long non-coding RNAs transcripts that negatively regulate gene expression by directly binding to the $3^{\prime}$-UTR of target mRNA [14]. Some studies have concluded that over $60 \%$ of human genes are regulated by miRNAs [15]. Increasing evidences has demonstrated that miRNAs not only regulate various biological processes [16-18], but also are associated with the carcinogenesis and progression of diverse human cancers, including CCA [19-21]. Serum analysis revealed that miR-1281, miR126 and miR-30b are significantly higher in CCA patients indicating a potential diagnostic value of these miRNAs in CCA [22]. The miR-17-92 cluster promotes CCA growth by decreasing expression of the tumor suppressor phosphatase and tensin homolog deleted on chromosome 10 (PTEN) [23]. High expression of miR-21 contributes to CCA metastasis [24].

In this study, we focused on a novel cancer-related miRNA, miR-191. Studies have shown that miR-191 is involved in multiple human cancers' initiation and progression [25, 26]. Liu et al. reported that miR-191 plays key roles in pancreatic cancer and serves as an unfavorable prognostic marker for pancreatic cancer patients [27]. In addition, a recent study documented that miR-191 could facilitate breast cancer progression via affecting the P53-miR-191-SOX4 regulatory loop [28]. Commonly, miRNAs regulate downstream targets at the post-transcriptional level, and competing endogenous RNAs(ceRNAs) are the primary mechanism by which miRNAs are regulated in vivo. Different specific targets of miR-191 have been identified including TIMP3, MDM4-C and DAPK1 [29-31]. The findings above prompted us to further evaluate whether miR-191 exerts its effects via a similar mechanism in CCA. According to predictions made using "TargetScan and MicroRNA.org", secreted frizzled frizzled-related protein-1 (sFRP1) was selected as the target of miR-191.

In this study, we aimed to investigate the molecular mechanism underlying miR-191's role in CCA. First, we examined the expression of miR-191 in CCA cells and explored its effects on these cells' survival. The results indicated that miR-191was over-expressed in all CCA cell lines that we evaluated, and was associated with cell viability and apoptosis of CCA. Moreover, miR-191 regulated the Wnt/ $\beta$-catenin signaling pathway by directly suppressing its target gene sFRP1. In addition, co-transfection of sFRP1 small interfering RNA (siRNA) with miR-191 inhibitor sequence reactivated the Wnt/ $\beta$-catenin signaling pathway, and restored colony formation ability and regained cell viability. Thus, our work provides a vital role of miR-191 in CCA, and shows that miR-191 is a potential target of CCA therapy.

\section{Materials and Methods}

\section{Human tissues and cell culture}

A total of 21 pairs of CCA tissues and their adjacent normal tissues were obtained from patients who underwent surgical procedures at the Second Affiliated Hospital of Harbin Medical University. All of the patients provided written consent and approval was obtained from the Ethics Committee of the Second Affiliated Hospital of Harbin Medical University. Human intrahepatic biliary epithelial cell (HiBECs), and all six CCA cell lines (QBC939, HUH28, HuCCT1, RBE, CCLP1 and TFK1) were obtained from the Cell Bank of Chinese Academy of Sciences (Shanghai, China). All cells were cultured in Dulbecco's modified Eagle medium (Invitrogen, Carlsbad, CA, USA), supplemented with $10 \%$ fetal bovine serum (Invitrogen), $50 \mathrm{U} / \mathrm{mL}$ penicillin, and $50 \mu \mathrm{g} / \mathrm{mL}$ streptomycin (Invitrogen). Cells were maintained at $37^{\circ} \mathrm{C}$ in a humidified incubator at 5\% $\mathrm{CO} 2$. 


\section{Cellular Physiology Cell Physiol Biochem 2018;49:1933-1942

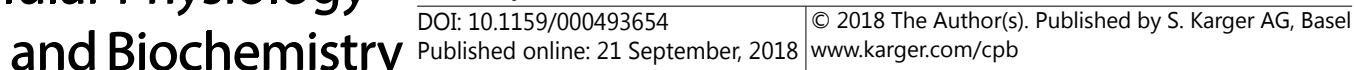

\section{miRNA and siRNA transfection}

miR-191 mimics (cat \#. B06001), miR-191 inhibitor sequences (cat \#. B05001), sFRP1 siRNA(cat \#. A01001) and corresponding negative control (NC) sequence were all purchased from GenePharma, (Shanghai, China).

RBE cells were seeded $24 \mathrm{~h}$ before transfection. miR-191 mimics, inhibitor or sFRP1 siRNA was transfected using Lipofectamine 2000 (Invitrogen) with serum-free medium. Five hours after transfection, cells were changed to complete medium. Cell lysates were harvested at $48 \mathrm{~h}$ after transfection.

\section{RNA extraction and quantitative real-time PCR}

Total RNA was extracted using TRIzol reagent (Invitrogen) according to the manufacturer's protocol. For regular gene expression analysis, RNAs were reverse transcribed into cDNA using Superscriptase II (Invitrogen). Quantitative real-time PCR (qRT-PCR) was performed using Power SYBR® Green PCR Master Mix (Life Technologies, Carlsbad, CA, USA). The following primer sets were used for qRT-PCR:

sFRP1-F: 5' - ACGTGGGCTACAAGAAGATGG -3';

sFRP1-R: 5' - CAGCGACACGGGTAGATGG -3';

GAPDH-F: 5' - AGCCTCCCGCTTCGCTCTCT -3';

GAPDH-R: 5' - GCGCCCAATACGACCAAATCCGT -3'.

The Hairpin-itmiRNAs qPCR Quantitation Kit (Cat \#. E01006, GenePhamar) was used to measure miR-191 expression. In brief, RNAs were reverse transcribed using miR-191 specific stem-loop reverse transcription primer to generate cDNA. The level of miR-191 was detected by qRT-PCR by specific primer set and molecular beacon probes. GAPDH was used for normalization.

\section{Antibodies and western blotting}

Whole-cell protein extracts collected from cells were prepared with RIPA lysis buffer containing a protease inhibitor cocktail (Roche, Basel, Switzerland). Nuclear proteins were isolated using a Minute Cytoplasmic and Nuclear Extraction Kit (Invent Biotechnologies, Inc., Plymouth, MN, USA). Equal amounts of proteins were separated by sodium dodecyl sulfate polyacrylamide gel electrophoresis and transferred to nitrocellulose membrane (Pall Corp., Port Washington, NY, USA). After blocking, the membranes were probed with primary antibodies against actin, survivin, c-myc (Santa Cruz Biotechnology, Dallas, TX, USA), $\beta$-catenin, glycogen synthase kinase $3 \beta$ (GSK3 $\beta$ ), pSer9-GSK3 $\beta$ (Cell Signaling Technology, Danvers, MA, USA) and sFRP1 (Abcam, Cambridge, UK). After washing and incubating with rabbit or mouse secondary antibodies (Cell Signaling Technology), the blots were visualized by electrochemiluminescence reagent (GE Healthcare, Chicago, IL, USA).

\section{Cell Counting Kit-8cell viability assay}

RBE cells were tranfected with indicated reagents according to experimental aim. Twenty-four hours after transfection, cells were transferred into 96-well plates at a density of $2 \times 10^{3}$ cells per well. Cell viability was assessed using a Cell Counting Kit-8 (CCK-8, Dojindo, Kumamoto,Japan) at days 0, 2 and 4.

\section{Colony formation assays}

RBE cells were transfected with the indicated reagents according to experimental aim. Twenty-four hours after transfection, 800 cells were counted and seeded in 6-cm dishes. After 10 days, colonies were stained with $0.1 \%$ crystal violet in $20 \%$ methanol for $15 \mathrm{~min}$. The samples were photographed and the numbers of visible colonies were counted.

\section{Acridine orange/ethidium bromide (AO/EB) fluorescence staining}

RBE cells were transfected with miR-191 inhibitor or control sequence. The cells were incubated with AO/EB solution for 5 min (Solarbio, Beijing, China). Cellular morphological changes were examined by fluorescence microscopy at $200 \times$ magnification. The percentage of apoptotic cells was calculated by the following formula: apoptotic rate (\%) = (number of apoptotic cells)/ (number of all cells counted). 


\section{Cellular Physiology Cell Physiol Biochem 2018;49:1933-1942

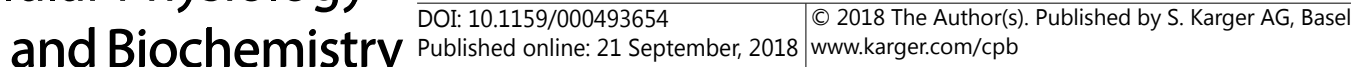 \\ Kang et al.: miR-191 Inhibition Induces Cholangiocarcinoma Cell Apoptosis}

Luciferase reporter assay

The wild-type miR-191 binding site on SFRP1 (sFRP1-WT) and binding site mutant sequence (sFRP1Mut) were subcloned into the pMIR-REPORT Luciferase vector (Ambion, Austin, TX,USA). RBE cells were seeded in 6-well plates, and transfected with the indicated components using Lipofectamine2000 for $48 \mathrm{~h}$. Luciferase activity was assessed with the Dual Luciferase reporter 1000 Assay System (Promega, Madison, Wisconsin,USA). The activity of Renilla luciferase was used for normalization.

\section{Data analysis}

Data were obtained from at least three independent experiments and are presented as the mean \pm standard deviation. Data were evaluated by unpaired Student's t test. The linear correlation coefficient (Pearson's $r$ ) was calculated to determine the correlation between miR-191 and sFRP1 expression in clinical samples. $\mathrm{P}<0.05$ was considered to represent a significant difference.

\section{Results}

miR-19 is up-regulated in CCA cells and specimens and maintains CCA cell survival

To test the expression of miR-191 in CCA cells, six CCA cell lines and HiBEC, which served as normal control, were collected. The level of miR-191 was measured by qRT-PCR. The data showed that although a diversity of expression levels was observed, all CCA cell lines harbored a much higher level of miR-191 compared with HiBECs (Fig. 1A). Moreover, 21 pairs of CCA tissues and their adjacent normal tissues were examined for the expression levels of miR-191. qRT-PCR results indicated that the expression level of miR-191 was significantly increased in CCA tissues compared with that in adjacent normal tissues (Fig. 1B). To uncover the effects of miR-191 on CCA, RBE cells were transfected with miR-191 inhibitor or its corresponding NC. CCK-8 assay and colony formation assay were performed to assess the cell viability. The data revealed that miR-191 inhibitor significantly reduced the level of miR-191 in RBE cells (Fig. 1C). CCK-8 assay showed that the cell viability was reduced by miR-191 knockdown (Fig. 1D). miR-191 inhibitor transfection also led to a decreased number of colonies formed (Fig. 1E). Consistent with these data, we found that knockdown of miR-191 led to an increased population of apoptotic cells as measured by AO/EB staining (Fig. 1F). Thus all these results indicate that miR-191 was over-expressed in CCA cells and maintains these cells' survival.

sFRP1 is a direct target of miR-191

The conventional mechanism by which miRNAs exert their effects is by binding to the $3^{\prime}$--UTR of target mRNA causing its degradation or translation inhibition. By interrogating a bioinformatics database using TargetScan and Microrna.org, we found that sFRP1 is a potential target of miR-191 (Fig. 2A). Both qRT-PCR and western blot analysis showed that sFRP1 level was negatively correlated with the level of miR-191 (Fig. 2B, C). Further, luciferase assay was performed to demonstrate whether sFRP1 was a direct target of miR191. Intriguingly, reduced luciferase activity was observed in cells co-transfected with miR$191 \mathrm{mimic} / \mathrm{sFRP1-WT}$. However, miR-191 mimic did not affect the luciferase activity in the sFRP1 MUT group (Fig. 2D). To determine the correlation between miR-191 expression and sFRP1 level, we examined the mRNA levels of sFRP1 in the same set of specimens, and qRTPCR results indicated that the miR-191 expression levels were inversely correlated with sFRP1 expression (Fig. 2E, F). These data revealed that sFRP1 was a direct target of miR-191.

miR-191 downregulation interferes with $W n t / \beta$-catenin signaling

It is well known that sFRP1 is a negative regulator of the Wnt/ $\beta$-catenin signaling pathway. Since sFRP1 is a direct target of miR-191, we asked whether miR-191 could regulate Wnt/ $\beta$-catenin signaling by targeting sFRP1. Western blot analysis revealed that miR-191 inhibitor transfection dramatically decreased $\beta$-catenin levels, especially in the nuclear fraction (Fig. 3A, B). The phosphorylation of GSK3 $\beta$ on Ser9 site was much higher 


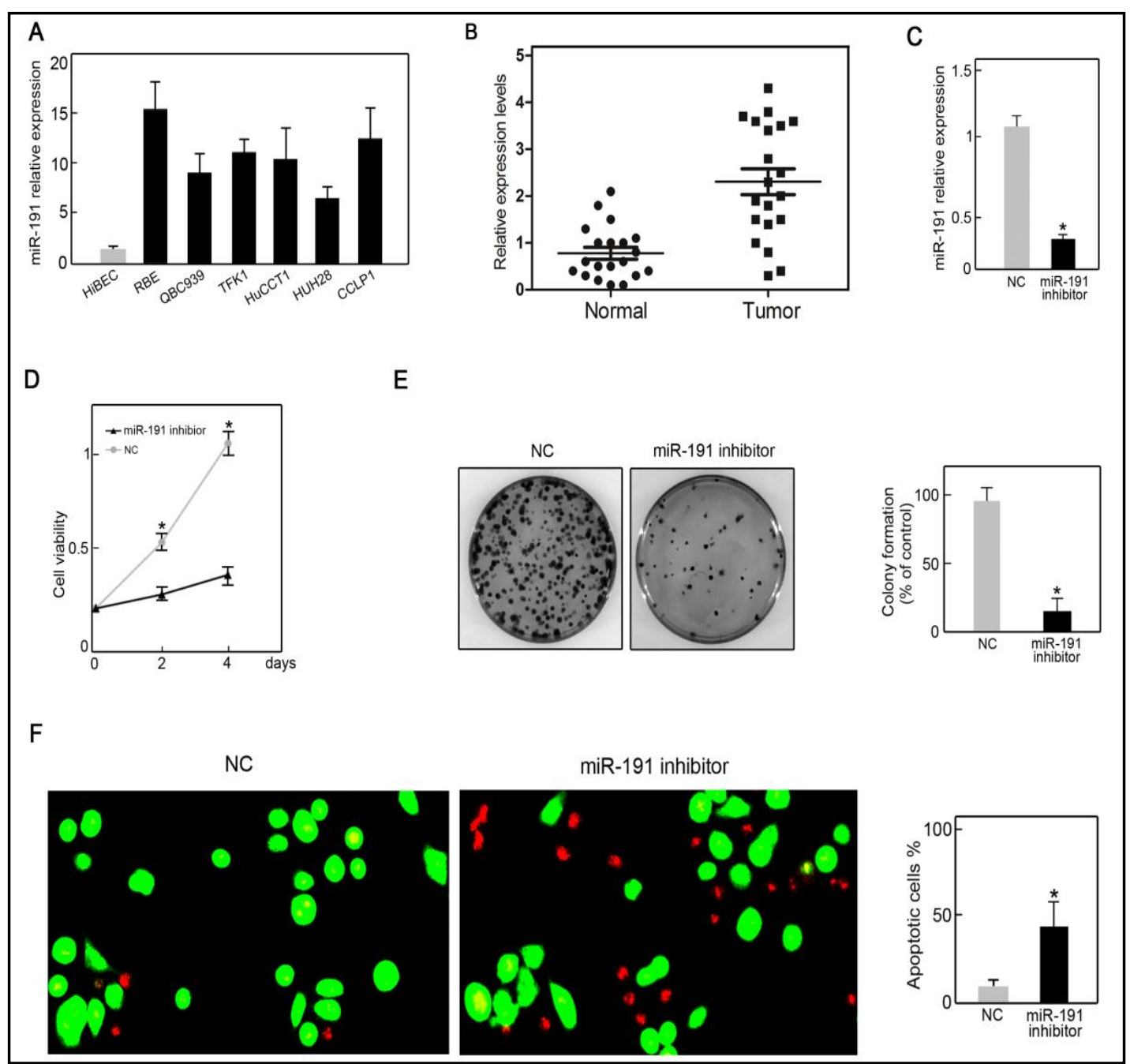

Fig. 1. miR-19 is up-regulated in CCA cells and maintainsCCA cell survival. (A). miR-191 was up-regulated in CCA cell lines. (B). Relative expression levels of miR-191 in adjacent normal tissues and CCA tissues. (C). miR-191 level was suppressed by miR-191 inhibitor transfection. (D). RBE cells transfected with miR-191 inhibitor or NC sequence were cultured for 4 days, and cell viability was analyzed by CCK- 8 assay at days 0 , 2, and 4. (E). RBE cells transfected with miR-191 inhibitor or NC sequence were seeded into6-cm dishes at a density of 800 cells/dish. Colony formation was assessed by crystal violet staining. (F). RBE cells transfected with miR-191 inhibitor or NC sequence were subjected to AO/EB staining to detect changes in the nucleus. The orange-colored region indicates initiation of apoptosis. ${ }^{*} \mathrm{P}<0.05$ vs. control $(\mathrm{n}=3$ independent experiments for each condition).

upon down-regulation of miR-191 compared with NC transfected cells, indicating blocked GSK3 $\beta$ activity (Fig. 3C). The expression of two important target genes of Wnt/ $\beta$-catenin signaling, survivin and c-myc, was reduced upon miR-191 inhibitor transfection (Fig. 3D). These data suggest that miR-191knockdown in RBE cells inhibited Wnt/ $\beta$-catenin signaling.

\section{miR-191 regulates Wnt/ $\beta$-catenin signaling pathway via sFRP1}

To determine whether miR-191 regulated Wnt/ $\beta$-catenin signaling via its target gene sFRP1, sFRP1 siRNA was co-transfected with miR-191 inhibitor into RBE cells. Western blot analysis showed that sFRP1 expression was suppressed by sFRP1 siRNA (Fig. 4A). Western blot analysis also demonstrated that the increase in the level of GSK3 $\beta$ phosphorylation seen with miR-191 inhibition was reversed (Fig. 4B). Moreover, the expression of survivin

\section{KARGER}


A

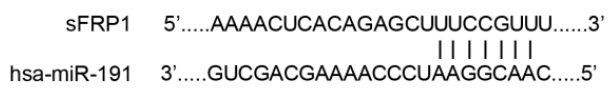

C

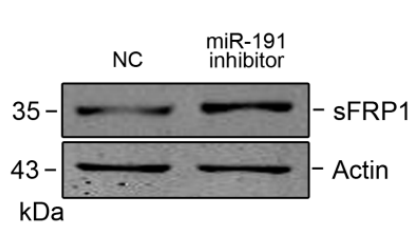

E

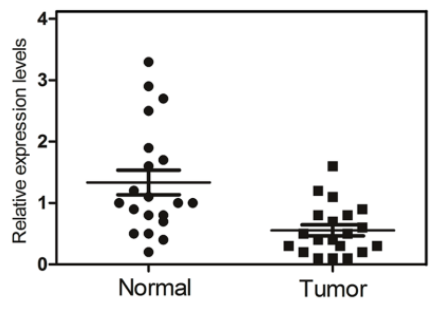

$\mathrm{F}$
B

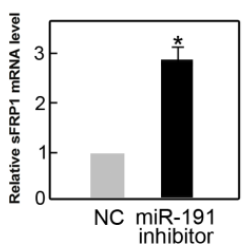

D

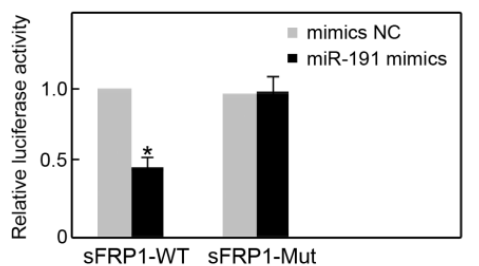

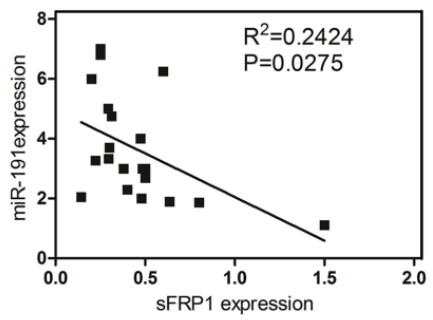

Fig. 2. sFRP1 is a direct target of miR-191. (A). Schematic diagram of the miR-191 binding site on sFRP1. (B). Knockdown of miR-181 increased the sFRP1 mRNA level. (C). Knockdown of miR-191 increased the sFRP1 protein level. (D). Luciferase reporter assay. RBE cells were co-transfected with a luciferase construct fused with the wild-type (sFRP1-WT) or site mutant (sFRP1-MUT) 3'-UTR of sFRP1 and miR-191 mimic or NC mimic. Luciferase activity is reported relative to that of Renilla. (E).Relative expression levels of sFRP1 in adjacent normal tissues and CCA tissues. (F). Correlation between miR-191 expression and sFRP1 expression in clinical samples. ${ }^{*} \mathrm{P}<0.05$ vs. control ( $\mathrm{n}=3$ independent experiments for each condition).

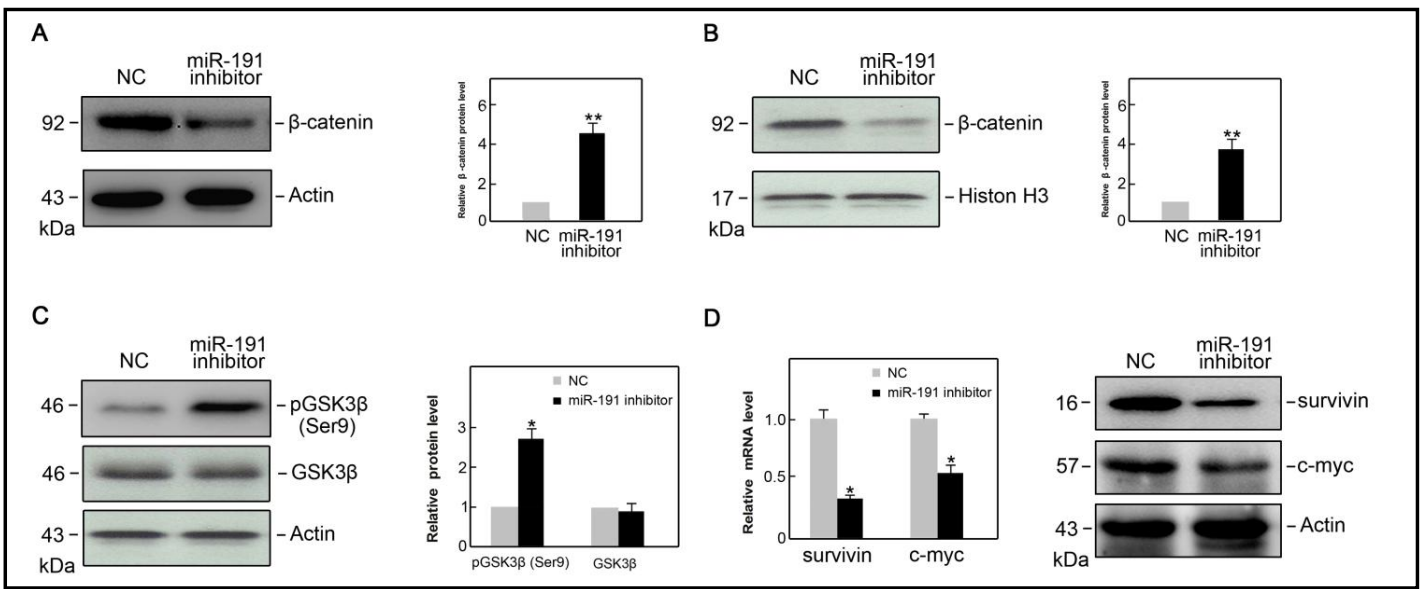

Fig. 3. miR-191 downregulation interferes with the Wnt/ $\beta$-catenin signalingRBE cells were transfected with miR-191 inhibitor or NC sequence for $48 \mathrm{~h}$. (A). The level of $\beta$-catenin inwhole-cell lysates was measured by western blot. (B). Level of $\beta$-catenin in the nuclear fraction was measured by western blot. (C). miR191 knockdown increased GSK3 $\beta$ phosphorylation at Ser9. (D). miR-191 knockdown reduced surviving and c-myc expression. ${ }^{*} \mathrm{P}<0.05,{ }^{* *} \mathrm{P}<0.001$ vs. control ( $\mathrm{n}=3$ independent experiments for each condition). 


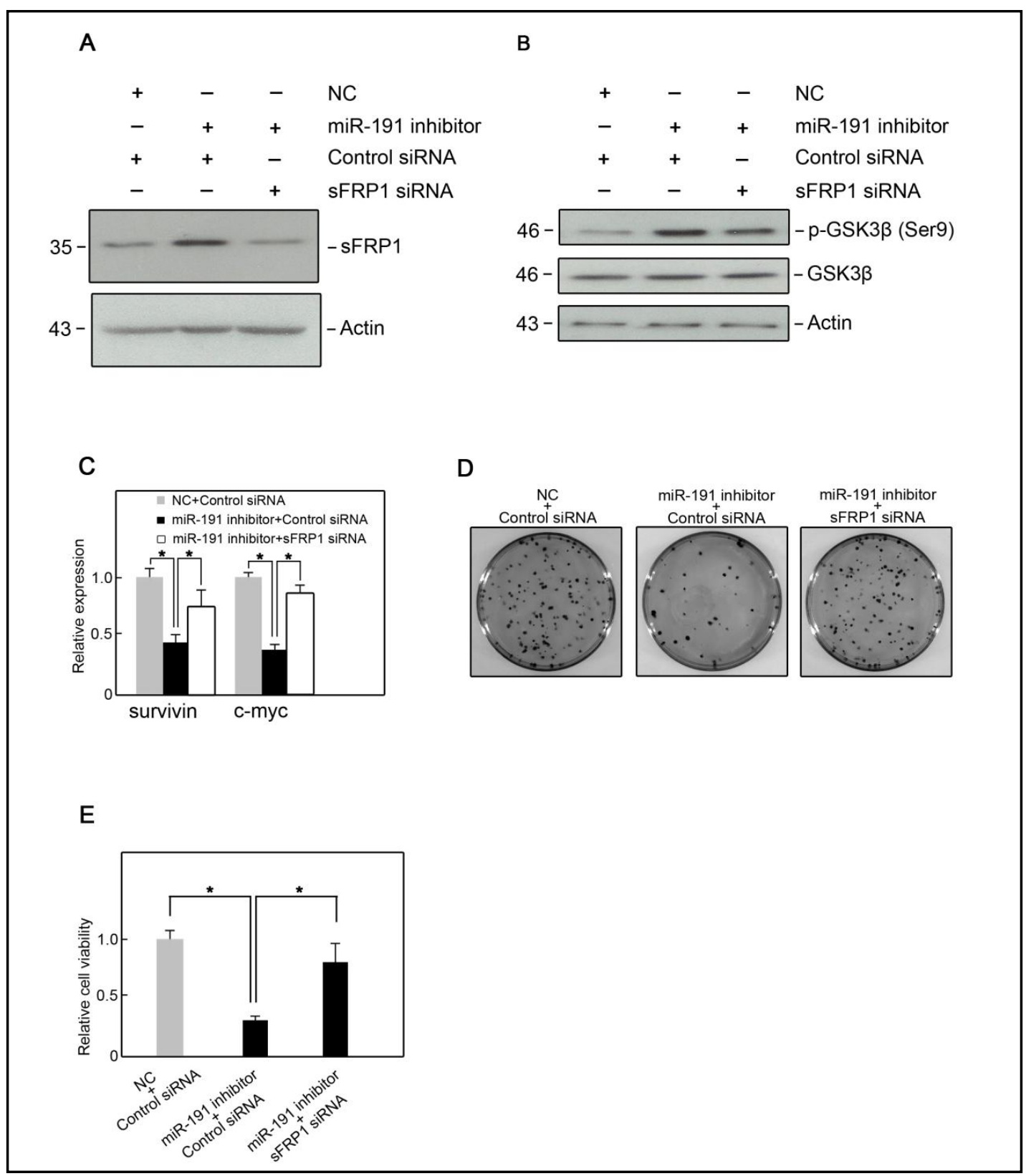

Fig. 4. miR-191 regulates the $\mathrm{Wnt} / \beta$-catenin signaling pathway via sFRP1RBE cells were co-transfected with the indicated reagents for $48 \mathrm{~h}$ (A). The level of sFRP1 was measured by western blot. (B). sFRP1 siRNA co-transfection with miR-191 inhibitor reversed the increase in GSK3 $\beta$ phosphorylation observed when RBE cells were treated with miR-191 inhibitor alone. (C). sFRP1 siRNA co-transfection with miR-191 inhibitor restored surviving and c-myc expression. (D). sFRP1 siRNA co-transfection with miR-191 inhibitor restored the colony formation ability of RBE cells. (E). SFRP1 siRNA co-transfection with miR-191 inhibitor restored cell viability in RBE cells. ${ }^{*} \mathrm{P}<0.05$ vs. control ( $\mathrm{n}=3$ independent experiments for each condition).

and c-myc was restored by sFRP1 siRNA co-transfection (Fig. 4C). Colony formation assay validated that co-transfection of SFRP1 siRNA with miR-191 inhibitor restored the formation ability of A59 cells (Fig. 4D). CCK-8 assay showed that RBE cell viability was regained by sFRP1 siRNA co-transfection (Fig. 4E). These results indicated that miR-191 regulates Wnt/ $\beta$-catenin signaling via sFRP1 and thus participates in maintaining RBE cell viability. 


\section{Cellular Physiology Cell Physiol Biochem 2018;49:1933-1942

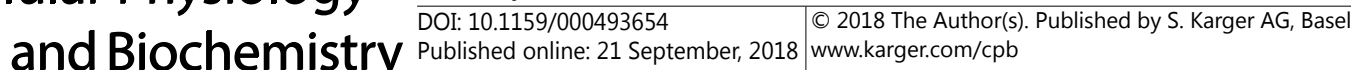 \\ Kang et al.: miR-191 Inhibition Induces Cholangiocarcinoma Cell Apoptosis}

\section{Discussion}

It is crucial to understand the molecular mechanisms of CCA carcinogenesis and its progression for developing new effective therapeutic strategies. Aberrant expression of miRNAs often occurs in CCA and plays critical roles in its progression [32]. Thus, it is critical to uncover the function of miRNAs in CCA and their mechanisms. In this research, we focus on miR-191 to investigate its molecular mechanism in CCA. We found that miR-191 was over-expressioned in all six CCA cell lines compared with HiBECs. Knock-down of miR-191 inhibited RBE cell growth and the impaired the colony formation ability.

As is well known, miRNAs suppress target gene expression usually by binding the 3 'UTR of target mRNAs. Many genes, such as Egr-1, C/EBP $\beta$, Tmod2 and ChK2, have been identified as miR-191 targets [33-36]. Here we screened potential target genes of miR-191 using the TargetScan and MicroRNA.org and found sFRP1 to be a viable candidate. Using miR-191 mimics or inhibitor to alter the expression level of miR-191 in RBE cells, we found that the sFRP1 level was negatively correlated with miR-191 expression. This observation is consistent with the conventional manner by which miRNAs regulate target expression. Luciferase reporter assay validated that sFRP1 is a direct target of miR-191.

It is well documented that SFRP1 is a negative regulator of the Wnt/ $\beta$-catenin signaling pathway [37, 38]. sFRP1 can bind to the Wnt protein though its CRD domain [39]. This interaction between sFRPs and Wnt proteins prevents the Wnt protein binding to frizzled receptors and in turn shuts down Wnt/ $\beta$-catenin signaling [40]. Masses of studies have shown that Wnt/ $\beta$-catenin signaling pathway is quite critical for CCA carcinogenesis and its progression $[41,42]$. We identified sFRP1as a direct target of miR-191, and further found that miR-191 regulates the $W n t / \beta$-catenin signaling pathway via targeting sFRP1. Knockdown of miR-191 inactivated Wnt/ $\beta$-catenin signaling characterized by decreased $\beta$-catenin level, increased GSK3 $\beta$ phosphorylation and reduced expression of two important target genes of Wnt/ $\beta$-catenin signaling, survivin and c-mycBy co-transfection of SFRP1 siRNA with miR191 inhibitor sequence, we found that the $\mathrm{Wnt} / \beta$-catenin signaling pathway was reactivated and the colony formation ability of RBE cells was restored, indicating that miR-191 indeed restored $W n t / \beta$-catenin signaling via SFRP1.

Based on these findings, we demonstrate a novel insight into miR-191 biological function in CCA. Our findings suggest that miR-191 is a potential therapeutic target of CCA treatment.

\section{Acknowledgements}

This research was supported by the Department of Science Research Project in Heilongjiang Province (No. GC12C304-1) and the Health and Family Planning Commission Research Project of Heilongjiang Province (Grant No. 2017-063).

\section{Disclosure Statement}

The authors declare that there is no conflict of interests regarding the publication of this paper.

\section{References}

1 Khan SA, Thomas HC, Davidson BR, Taylor-Robinson SD: Cholangiocarcinoma. Lancet 2005;366:13031314.

2 Mavros MN, Economopoulos KP, Alexiou VG, Pawlik TM: Treatment and prognosis for patients with intrahepatic cholangiocarcinoma: Systematic review and meta-analysis. JAMA surg 2014;149:565-574. 


\section{Cellular Physiology Cell Physiol Biochem 2018;49:1933-1942 \begin{tabular}{ll|l} 
DOI: 10.1159/000493654_0 2018 The Author(s). Published by S. Karger AG, Basel \\
and Biochemistry
\end{tabular} and Biochemistry Published online: 21 September, 2018 www.karger.com/cpb}

Kang et al.: miR-191 Inhibition Induces Cholangiocarcinoma Cell Apoptosis

-3 Shen FZ, Zhang BY, Feng YJ, Jia ZX, An B, Liu CC, Deng XY, Kulkarni AD, Lu Y: Current research in perineural invasion of cholangiocarcinoma. J Exp Clin Cancer Res 2010;29:24. doi:10.1186/1756-9966-29-24.

-4 Shi RY, Yang XR, Shen QJ, Yang LX, Xu Y, Qiu SJ, Sun YF, Zhang X, Wang Z, Zhu K, Qin WX,Tang ZY, Fan J, Zhou J: High expression of Dickkopf-related protein 1 is related to lymphatic metastasis and indicates poor prognosis in intrahepatic cholangiocarcinoma patients after surgery. Cancer 2013;119:99-1003.

5 Wang LJ, He CC, Sui X, Cai MJ, Zhou CY, Ma JL, Wu L, Wang H, Han SX, Zhu Q: Mir-21promotes intrahepatic cholangiocarcinoma proliferation and growth in vitro and in vivo by targeting PTPN14 and PTEN. Oncotarget 2015;6:5932-5946.

-6 Wang J, Xie H, Ling Q, Lu D, Lv Z, Zhuang R, Liu Z, Wei X, Zhou L, Xu X, Zheng S: Coding-noncoding gene expression in intrahepatic cholangiocarcinoma. Trans Res 2016;168:107-121.

-7 Saha SK, Parachoniak CA, Ghanta KS, Fitamant J, Ross KN, Najem MS, Gurumurthy S, AkbayEA, Sia D, Cornella H, Miltiadous O, Walesky C, Deshpande V, Zhu AX, Hezel AF, Yen KE, StraleyKS, Travins J, PopoviciMuller J, Gliser C et al.: Mutant IDH inhibits HNF-4alpha to block hepatocyte differentiation and promote biliary cancer. Nature 2014;513:110-114.

-8 Zhou G, Yang Z, Wang X, Tao R, Zhou Y: TRAIL Enhances Shikonin Induced Apoptosis through ROS/JNK Signaling in CCA Cells. Cell Physiol Biochem 2017;42:1073-1086.

-9 Lu X, Zhou C, Li R, Deng Y, Zhao L, Zhai W: Long Noncoding RNA AFAP1-AS1 promoted tumor growth and invasion in CCA. Cell Physiol Biochem 2017;42:222-230.

10 DeOliveira ML: Liver transplantation for cholangiocarcinoma. Curr Opin Organ Transplant 2014;19:245252.

11 Miura JT, Johnston FM, Tsai S, George B, Thomas J, Eastwood D, Banerjee A, Christians KK,Turaga KK, Pawlik TM, Clark Gamblin T: Chemotherapy for surgically resected intrahepatic cholangiocarcinoma. Ann Surg Onco 2015;22:3716-3723.

$>12$ Ben-Josef E, Guthrie KA, El-Khoueiry AB, Corless CL, Zalupski MM, Lowy AM, Thomas CR,Jr., Alberts SR, Dawson LA, Micetich KC, Thomas MB, Siegel AB, Blanke CD:SWOG S0809: A phase ii intergroup trial of adjuvant capecitabine and gemcitabine followed by radiotherapy and concurrent capecitabine in extrahepatic cholangiocarcinoma and gallbladder carcinoma. J Clin Onco 2015;33:2617-2622.

13 Li W, Man W, Guo H, Yang P: Clinical study of transcatheter arterial chemoembolization combined with microwave ablation in the treatment of advanced hepatocellular carcinoma. J Cancer Res Ther 2016;12:C217-C220.

14 Bartel DP: MicroRNA: Target recognition and regulatory functions. Cell 2009;136:215-233.

15 Friedman RC, Farh KK, Burge CB, Bartel DP: Most mammalian mRNAs are conserved targets of microRNAs. Genome Res 2009;19:92-105.

16 Diaz NF, Cruz-Resendiz MS, Flores-Herrera H, Garcia-Lopez G, Molina-Hernandez A: MicroRNAs in central nervous system development. Rev Neurosci 2014; 25:675-686.

$\checkmark 17$ Shivdasani RA: MicroRNAs: Regulators of gene expression and cell differentiation. Blood 2006;108:36463653.

18 Smith-Vikos T, Slack FJ: MicroRNAs and their roles in aging. J Cell Sci 2012;125:7-17.

19 Cheng CJ, Bahal R, Babar IA, Pincus Z, Barrera F, Liu C, Svoronos A, Braddock DT, Glazer PM, Engelman DM, Saltzman WM, Slack FJ: MicroRNA silencing for cancer therapy targeted to the tumor microenvironment. Nature 2015;518:107-110.

20 Mouw JK, Yui Y, Damiano L, Bainer RO, Lakins JN, Acerbi I, Ou G, Wijekoon AC, Levental KR, Gilbert PM, Hwang ES, Chen YY, Weaver VM: Tissue mechanics modulate microRNA-dependent PTEN expression to regulate malignant progression. Nature medicine 2014;20:360-367.

21 Yao L, Han C, Song K, Zhang J, Lim K, Wu T: Omega-3 polyunsaturated fatty acids upregulate 15-PGDH expression in cholangiocarcinoma cells by inhibiting mir-26a/b expression. Cancer Res 2015;75:13881398.

22 Voigtlander T, Gupta SK, Thum S, Fendrich J, Manns MP, Lankisch TO, Thum T: MicroRNAs in serum and bile of patients with primary sclerosing cholangitis and/or cholangiocarcinoma. PloS one 2015;10:e0139305.

23 Zhu H, Han C, Lu D, Wu T: miR-17-92 cluster promotes cholangiocarcinoma growth: Evidence for PTEN as downstream target and IL-6/Stat3 as upstream activator. Am J Pathol 2014;184:2828-2839. 


\section{Cellular Physiology Cell Physiol Biochem 2018;49:1933-1942 \begin{tabular}{l|l|l|l|} 
DOI: 10.1159/000493654 2018 The Author(s). Published by S. Karger AG, Basel & (c)
\end{tabular} and Biochemistry Published online: 21 September, 2018 www.karger.com/cpb}

Kang et al.: miR-191 Inhibition Induces Cholangiocarcinoma Cell Apoptosis

24 Chusorn P, Namwat N, Loilome W, Techasen A, Pairojkul C, Khuntikeo N, Dechakhamphu A,Talabnin C, Chan-On W, Ong CK, Teh BT, Yongvanit P: Overexpression of microRNA-21 regulating PDCD4 during tumorigenesis of liver fluke-associated cholangiocarcinoma contributes to tumor growthand metastasis. Tumour Biol 2013;34:1579-1588.

25 Nagpal N, Kulshreshtha R: miR-191: An emerging player in disease biology. Front Genet 2014;5:99.

-26 Di Leva G, Piovan C, Gasparini P, Ngankeu A, Taccioli C, Briskin D, Cheung DG, Bolon B, Anderlucci L, Alder H, Nuovo G, Li M, Iorio MV, Galasso M, Santhanam R, Marcucci G, Perrotti D,Powell KA, Bratasz A, Garofalo M, Nephew KP, Croce CM: Estrogen mediated-activation of miR-191/425 cluster modulates tumorigenicity of breast cancer cells depending on estrogen receptor status. PLoS Genet 2013;9:e1003311.

-27 Sharma S, Nagpal N, Ghosh PC, Kulshreshtha R: P53-miR-191-SOX4 regulatory loop affects apoptosis in breast cancer. RNA 2017;23:1237-1246.

28 Qin S, Zhu Y, Ai F, Li Y, Bai B, Yao W, Dong L: MicroRNA-191 correlates with poor prognosis of colorectal carcinoma and plays multiple roles by targeting tissue inhibitor of metalloprotease 3. J Clin Endocrinol Metab 2011;96:E1915-1924.

29 Liu H, Xu XF, Zhao Y, Tang MC, Zhou YQ Lu J, Gao FH: MicroRNA-191 promotes pancreatic cancer progression by targeting USP10. Tumour Biol 2014;35:12157-12163.

-30 Wynendaele J, Böhnke A, Leucci E, Nielsen SJ, Lambertz I, Hammer S, Sbrzesny N, Kubitza D, Wolf A, Gradhand E, Balschun K, Braicu I, Sehouli J, Darb-Esfahani S, Denkert C, Thomssen C, Hauptmann S, Lund A, Marine JC, Bartel F: An illegitimate microRNA target site within the 3' UTR of MDM4 affects ovarian cancer progression and chemosensitivity. Cancer Res 2010;70:9641-9649.

-31 Tian X, Xu L, Wang P: MiR-191 inhibits TNF- $\alpha$ induced apoptosis of ovarian endometriosis and endometrioid carcinoma cells by targeting DAPK1. Int J Clin Exp Pathol 2015;8:4933-4942.

-32 Plieskatt JL, Rinaldi G, Feng Y, Peng J, Yonglitthipagon P, Easley S, Laha T, Pairojkul C,Bhudhisawasdi V, Sripa B, Brindley PJ, Mulvenna JP, Bethony JM: Distinct miRNA signatures associate with subtypes of cholangiocarcinoma from infection with the tumourigenic liver fluke Opisthorchis viverrini. J Hepatol 2014;61:850-858.

-33 Li Y, McRobb LS, Khachigian LM: MicroRNA miR-191 targets the zinc finger transcription factor Egr-1 and suppresses intimal thickening after carotid injury. Int J Cardiol 2016;212:299-302.

-34 Zhang XF, Li KK, Gao L, Li SZ, Chen K, Zhang JB, Wang D, Tu RF, Zhang JX, Tao KX, Wang G,Zhang XD: miR-191 promotes tumorigenesis of human colorectal cancer through targeting c/EBPbeta. Oncotarget 2015;6:4144-4158.

35 Hu Z, Yu D, Gu QH, Yang Y, Tu K, Zhu J, Li Z: miR-191 and miR-135 are required for long-lasting spine remodelling associated with synaptic long-term depression. Nat Commun 2014;5:3263.

-36 Huang YZ, Zhang J, Shao HY, Chen JP, Zhao HY: MicroRNA-191 promotes osteosarcoma cells proliferation by targeting checkpoint kinase 2. Tumour Biol 2015;36:6095-6101.

-37 Matsuda Y, Schlange T, Oakeley EJ, Boulay A, Hynes NE: WNT signaling enhances breast cancer cell motility and blockade of the WNT pathway by sFRP1 suppresses MDA-MB-231 xenograft growth. Breast Cancer Res 2009;11:R32.

38 Kawano Y, Kypta R: Secreted antagonists of the Wnt signalling pathway. science Cell Sci 2003;116:26272634.

-39 Xavier CP, Melikova M, Chuman Y, Uren A, Baljinnyam B, Rubin JS: Secreted Frizzled-related protein potentiation versus inhibition of Wnt3a/beta-catenin signaling. Cellular Signal 2014;26:94-101.

-40 Kawano Y, Diez S, Uysal-Onganer P, Darrington RS, Waxman J, Kypta RM: Secreted Frizzled-related protein-1 is a negative regulator of androgen receptor activity in prostate cancer. Br J Cancer 2009;100:1165-1174.

41 Wang W, Zhong W, Yuan J, Yan C, Hu S, Tong Y, Mao Y, Hu T, Zhang B, Song G: Involvement of Wnt/betacatenin signaling in the mesenchymal stem cells promote metastatic growth and chemoresistance of cholangiocarcinoma. Oncotarget 2015;6: 42276-42289.

42 Coulouarn C, Cavard C, Rubbia-Brandt L, Audebourg A, Dumont F, Jacques S, Just PA, Clement B, Gilgenkrantz H, Perret C, Terris B: Combined hepatocellular- cholangiocarcinomas exhibit progenitor features and activation of Wnt and TGF $\beta$ signaling pathways. Carcinogenesis 2012;33:1791-1796. 